\title{
Investigating of conceptions of learning biology with respect to gender, grade level and school type
}

\author{
Özlem Sadi ${ }^{1 a}$, and Mustafa Çevik ${ }^{2}$ \\ ${ }^{1}$ Karamanoglu Mehmetbey University,Education faculty, Department of Educational \\ Sciences, Karaman, 70100, Turkey \\ ${ }^{2}$ Karamanoğlu Mehmetbey University, Education Faculty, Department of Primary Education, \\ Karaman, 70100, Turkey
}

\begin{abstract}
The aim of this study was to describe the students' conceptions of learning biology (COLB) and investigate students' COLB with respect to gender, grade level and school type. COLB questionnaire was implemented in 1691 high school students. In general, this study recognized students preferred higher-level conceptions of learning (increasing knowledge, application, understanding and seeing in a new way) to lower-level conceptions (memorizing, preparing for exams and calculating and practicing). Based on MANOVA results, there are statistically significant correlation between grade level, school type and categories of conceptions of learning biology. However, no interaction between students' gender and COLB factors was found, indicating that there was no statistically significant mean difference between male and female students with respect to all seven categories of COLB.
\end{abstract}

Keywords: conceptions of learning, gender, grade level, school type

\section{Introduction}

Educational researchers have been conducting many studies in the field of science education to research the factors that might have an effect on students' academic achievement and suggesting how these factors can be used in favor of students and teachers. When the related literature is searched, several different factors like students' gender, age, grade level, socioeconomic status and their cognitive and motivational characteristics, learning approaches and strategies, attitudes towards a topic, epistemological beliefs and conceptions of learning can be given as examples to these factors. Among abovementioned factors, research studies have been frequently focused on conceptions of learning and the relations between students' conceptions of learning and their epistemic views, learning strategies, approaches and self-efficacy recently $[12,15]$.

\footnotetext{
a Corresponding author: oturksadi@hotmail.com
} 
Conceptions of learning have been identified as students' beliefs about the subject or process and the learning ways they preferred [2, 4]. Vermunt and Vermetten [22] defined that conceptions of learning related with what the learners think about their learning goals and values and also, perceptions of learning process. The earliest research in this field was conducted by Saljo [14] with 90 college students. Saljo interviewed by the students about their conceptions of learning and five categories were determined based on the data analysis. The qualitatively different categories were increasing one's knowledge, memorizing, using the information acquired, making inferences, and evaluating the process to understand the reality. Then, Marton et.al [11] defined the new and the sixth category as 'changing as a person' and so, they considered the six aspects of students' conceptions of learning in a hierarchical order. Similarly, at 1999, Marshall and coworkers [10] conducted a qualitative study and categorized general conceptions of learning as (1) learning as memorizing definitions, equations and procedures, (2) learning as applying equations and procedures, (3) learning as making sense of physical concepts and procedures, (4) learning as seeing phenomena in the world in a new way, and (5) learning as a change as a person. Another qualitative study was carried out by Tsai [15] in Taiwan and he made interviews with 120 high school students by using phenomenographic method. According to study result, seven categories which are (1) memorizing, (2) preparing for tests, (3) calculating and practicing the tutorial problems, (4) increase of knowledge, (5) applying, (6) understanding, and (7) seeing in a new way, were identified. Similar to previous studies [22], Tsai [15] claimed that these conceptions are in hierarchical order and first three conceptions can be labeled as "lower-level conceptions" and last four conceptions can be labeled as "higher-level conceptions". Moreover, Vîrban [23] investigated the differences of gender and educational level in the conceptions of learning in Romania. The t-test results showed that there were significant mean differences between girls and boys on the understanding, personal change, skills development, ongoing process of information acquisition of conceptions of learning. However, there were no statistical differences between girls and boys on the acquisition of information of conceptions of learning. Also, educational level might be important factor for the students' conception of learning.

In addition, previous studies [10, 15] have showed, students' conceptions of learning can be connected with the educational majors even if their level is high school. Since conceptions of learning is domain dependent, educational researchers study students' conceptions of learning for physics, biology, and chemistry along with students' overall conceptions of learning under the name of science [4, 8]. For instance, Sadi and Lee [12] examine and compare science-major and literature-major students' conceptions of learning science (COLS). 'Conceptions of Learning Science' questionnaire was used to identify students in Science-Mathematics and Literature-Mathematics field. Results showed that science-major student' mean scores of COLS for 'memorizing,' 'preparing for the exam,' and 'increasing one's knowledge' factors were higher than those of literature-major students. On the other hand, literature-major students' mean scores of COLS have higher on 'calculating and practicing,' 'applying,' 'understanding,' and 'seeing in a new way' factors than science-major students' mean scores. Another study was conducted by Li, Liang and Tsai [8] to examine the relationships between conceptions of and approaches to learning in chemistry and investigate grade level differences in conceptions of learning chemistry. 'Conceptions of Learning Chemistry' (COLC) and 'Approaches to Learning Chemistry' (ALC) questionnaire were applied to identify 369 chemistry-major college students' beliefs about learning and approaches to learning chemistry. They categorized the COLC under four factors which are 'memorizing', 'testing', 'calculating and practicing' and 'transforming'. According to regression results, students who use surface approaches to learning chemistry, preferred lower level COLC (such as preferring memorizing and testing) and students who use deep approaches to learning chemistry preferred higher level 
COLC (such as increase of knowledge, applying understanding and seeing in a new way). Also, Li and coworkers stated that the higher grade students (undergraduate juniors and seniors) tend to have more high-level COLC than the lower grade students (freshmen and sophomores).Based on the suggestions of the above-mentioned researchers $[4,15]$, the conceptions of learning might be changed according to students' major and so, various scientific domains should be investigated to have deeper information about students' conceptions of learning (e.g. biology).

\subsection{Rationale of the study}

This study, describing the high school students' conceptions of learning biology (COLB) and investigating the students' COLB with respect to gender, grade level and school type, was undertaken on the basis of the some rationales. First of all, research has revealed that conceptions of learning might be effected by cultural differences (Purdie et al., [16] cited in 15, 3]. Li [8] emphasized that there might be some differences in American and Chinese college students' conceptions of learning depending on the culture. Moreover, Tsai [15] stated that in the conceptions of learning of Taiwanese high school students, "preparing for exams' as factor exists because of cultural characteristics. More recently, Lin, Liang, and Tsai [9] concluded that both 'memorizing' and 'understanding' are important in learning biology for Taiwan university students'. In Turkey, some studies were done to identify students' conceptions of learning by using qualitative and quantitative methods $[12,6,18$, $1,5]$ but it has not been widely used as in other countries. Additionally, these national studies did not mention about the high school students 'conceptions of learning biology; however, these studies interested in the senior Turkish preservice elementary science teachers' [6], biology student teachers' [5], university biology-major students [18] conceptions of learning. Accordingly, in the current study, it was aimed to identify the conceptions of learning biology of high school students who get education in Turkish cultures. Secondly, among the research studies conducted in Turkey, any study which specifically aims to find out the conceptualization of high school students' conceptions of learning biology with respect to gender, grade level and school type simultaneously. Some researchers examined whether students' conceptions of learning differ across gender, grade levels and field of study in different countries. For instance, Zeegers' [17] study an Australian university, suggested that more mature (experienced) students tended to use deep strategies to process their learning tasks in science. Additionally, in Taiwan, Chiou, Liang and Tsai [4] examined the gender differences in students' conceptions of learning biology (COLB). They found gender differences in COLB showing that female students tented to express more sophisticated COLB (increasing one's knowledge, understanding, and seeing in a new way) than male students. Particularly, there is no such a study whether gender, grade level and school type plays a role in high school students' conceptions of learning biology in Turkey. Thus, the aim of this study is to reveal how high school students conceptualized learning in biology. In this way, it will be possible to understand whether Turkish students have higher-level conceptions or lower-level conceptions and various solutions will be discussed for the students who have lower-level conceptions. Therefore, the current study is expected to make an important contribution to the related literature. 


\section{Methods}

This study is based on survey method to describe Turkish high school students' conceptions of learning biology (COLB) and to investigate the differences in students' COLB with respect to gender, grade level and school type.

\subsection{Participants}

The participants in this study included 1691 high school students in Turkey. All of the students had taken biology courses before participating in this study. All participants were administered COLB questionnaire to describe their conceptions of learning biology after permission was received from their teachers and school management. The gender distribution of the sample is 1093 female $(64.6 \%)$ and 598 male $(35.4 \%) .960$ students from 9th grade $(56.8 \%), 495$ students from 10th grade $(29.3 \%)$ and 236 students from 11 th grade (14\%) participated in the study. Moreover, the school type distribution of the students is 913 from Anatolian High School (Anadolu High School) (54\%), 131 from Science High School (7,7\%), 444 from Vocational High School ( 26.3\%) and 203 from Religious High Schools (Imam-Hatip High Schools). Convenience sampling was used to choose the sample.

\subsection{Instrument}

The 'Conceptions of Learning Biology' (COLB) questionnaire was used to identify high school students' conceptions of learning biology. The primary questionnaire, which was the 'Conceptions of Learning Science' (COLS) developed by [7], was adapted to biology. The original version of the questionnaire consists of 35 items and 7 factors. These factors are 'memorizing' (5 items), 'preparing for exams' (6 items), 'calculating and practicing' (5 items), 'increasing one's knowledge' (5 items), 'application' (5 items), 'understanding' (4 items) and 'seeing in a new way' ( 5 items). These factors have a certain hierarchy and the first three factors are defined as "lower-level conceptions of learning" and the last four factors are 'higher-level conceptions of learning' [8]. In the current study, COLS questionnaire, which was adapted to Turkish by Sadi and Uyar [13], was revised for biology since in this study the aim was to identify the students' COLB. The questionnaire, which was adapted in order to identify students' conceptions of learning biology, was analyzed by experts to order to test for its validity. Moreover, an exploratory factor analysis was conducted to test the factor structure of COLB.

\subsection{Data analysis}

An exploratory factor analysis was conducted on the answers of the high school students to COLB questionnaire. Then, in order to describe the general tendencies regarding conceptions of learning biology of students getting education in Turkey, descriptive statistics was carried out and mean scores were calculated for each factor of COLB. Finally, Multivariate analysis of variance (MANOVA) was conducted to identify the differences in gender, grade level and school types. 


\section{Results}

First of all, the factor analyses of COLB were conducted to test construct validity. First of all, Kaiser-Meyer-Olkin (KMO) and Bartlett's sphericity tests were calculated to see whether the data is suitable for factor analysis. KMO is expected to be higher than 0.50 for factorability. In view of the fact that the value obtained from KMO test was 0.905 for COLB and the value is close to 1 , so that the data could be modeled by factor analytic model [19]. Moreover, according to Bartlett sphericity test results, chi-square $\left(\chi^{2}\right)$ was $16424.40(\mathrm{p}<0.01)$ for COLB and null hypothesis was rejected. Therefore, the data has a normal multi-variable distribution and suitable for factor analysis [20].

According to the results of the exploratory factor analysis of the adapted version of the 'Conceptions of Learning Biology' (COLB) questionnaire, the 13th items of the scale were removed from the questionnaire since its factor load were lower than 0.40. After this item was removed from the questionnaire, the same analysis was conducted again for the remaining 34 items by using SPSS 15.0 statistics software package. Accordingly, 34 items under analysis were gathered under 7 factors whose Eigen values were over 1. It was found that all seven factors together which were considered important factors in the analysis explained most of the overall variance in the items and the variance regarding the scale. Also, the cronbach alfa reliability coefficient regarding the reliability of the COLB questionnaire was found to be 0.83 . The Cronbach Alfa reliability coefficient ranged from 0.60 to 0.79 for each factor. In educational researches, it is enough to have a general reliability coefficient over 0.60 in order to consider the test points reliable [21]. Also, the students have the highest mean in 'understanding' factor. Then, 'seeing in a new way' and 'increasing one's knowledge' factors have high means. However, "memorization" and "calculating and practicing" factors have lower means when compared with the factors explained above.

In the current study, the general tendencies regarding Turkish high school students' COLB and the statistical differences in gender, grade level and school type, descriptive and inferential statistics were conducted (Table 1).

Table 1.COLB mean scores of Turkish students with respect to gender, grade level and school type

\begin{tabular}{|c|c|c|c|c|c|c|c|}
\hline & Memorizing & $\begin{array}{l}\text { Preparing } \\
\text { for exams }\end{array}$ & $\begin{array}{l}\text { Calculating } \\
\text { and } \\
\text { Practicing }\end{array}$ & $\begin{array}{l}\text { Increasing } \\
\text { one's } \\
\text { knowledge }\end{array}$ & Application & Understanding & $\begin{array}{l}\text { Seeing in a } \\
\text { new way }\end{array}$ \\
\hline \multicolumn{8}{|l|}{ Gender } \\
\hline female & 3.02 & 3.00 & 2.98 & 3.67 & 3.32 & 3.68 & 3.67 \\
\hline male & 2.90 & 3.01 & 2.97 & 3.64 & 3.32 & 3.65 & 3.60 \\
\hline \multicolumn{8}{|l|}{$\begin{array}{l}\text { Grade } \\
\text { level }\end{array}$} \\
\hline $\begin{array}{l}\text { 9th grade } \\
10 \text { the }\end{array}$ & 2.98 & 3.03 & 2.98 & 3.69 & 3.37 & 3.70 & 3.68 \\
\hline grade & 2.98 & 3.02 & 2.99 & 3.63 & 3.27 & 3.63 & 3.57 \\
\hline 11 grade & 2.97 & 2.86 & 2.91 & 3.61 & 3.21 & 3.64 & 3.66 \\
\hline \multicolumn{8}{|l|}{$\begin{array}{l}\text { School } \\
\text { type }\end{array}$} \\
\hline A.H.S & 2.87 & 2.95 & 2.92 & 3.67 & 3.33 & 3.72 & 3.68 \\
\hline S.H.S & 3.08 & 3.02 & 2.94 & 3.76 & 3.36 & 3.81 & 3.60 \\
\hline V.H.S & 2.94 & 3.08 & 3.07 & 3.62 & 3.32 & 3.62 & 3.64 \\
\hline R.H.S & 3.47 & 3.06 & 3.04 & 3.61 & 3.27 & 3.49 & 3.52 \\
\hline
\end{tabular}

Note: Anatolian High school: AHS; Science High School: SHS; Vocational High School: VHS;Religious High School: RHS. 
As it is seen in the Table 1, in general, male and female students prefer to use higherlevel conceptions of learning biology. Also, 11th grade students mean score of preparing exams was lower than 9th and 10th grade students. Moreover, 9th grade students mean score of application was higher than 10th and 11th grade students. Finally, 9th and 11th grade students mean score of seeing in a new way was higher than 10th grade students. In addition, Table 1 showed that the students mean score of memorizing in Religious (ImamHatip) high Schools was higher than students in other schools.

In addition, students' COLB differences in gender, grade level and school type was given in Table 2. Results showed that COLB was not differing between girls and boys. However, there is a statistically meaningful difference between 9th, 10th and 11th grade students in terms of their mean scores for 'preparing for exams', 'application' and 'seeing in a new way' factors of COLB (Table 2). 9th and 10th grade students' mean scores for 'preparing for exams' conception of learning was higher than those of 11th grade students. And, 9th grade students' mean scores for 'application' was higher than those of 10th and 11 th grade students. Finally, 9th and 11th grade students' mean scores for 'seeing in a new way' factors of COLB was higher than those of 10th grade students.

Table 2. MANOVA summary for comparing all seven categories of COLB with respect to students' gender, grade level and school type

\begin{tabular}{llll}
\hline Effect & Pillai's Trace & F & Significance \\
\hline gender & 0.002 & 1.70 & 0.103 \\
grade level & 0.102 & 5.30 & $0.019^{* *}$ \\
school type & 0.150 & 6.01 & $0.000^{* *}$ \\
\hline
\end{tabular}

Note: **Significant at the .05 level.

Accordingly, there is a statistically meaningful difference between students in different school types in terms of 'memorizing', 'preparing for exams', 'calculating and practicing' and ' understanding' factors of COLB. In contrast students in other schools, students in Religious High School have a tendency towards learning biology as 'memorizing'. However, students in Anatolian and Vocational High school have higher mean values in the 'understanding' than students in High School. Also, students in Vocational High school have higher mean values in the 'preparing for exams' and 'calculating and practicing' learning conception.

\section{Discussion and conclusion}

The current study aims to investigate Turkish students' COLB differences in gender, grade level and school type. Firstly, the high school students had higher mean values in COLB for the factors such as 'increasing ones' knowledge, application, understanding and seeing in a new way' so that the students express higher-level COLB In fact, radical changes have been made in the Turkish curriculum since 2004 might have an effect on this result. Moreover, the results showed that there was no statistically significant difference for students' gender on categories of COLB. Although the researchers stated statistically mean differences on categories of conceptions of learning science scores [12], the current study considered the conceptions of learning in biology and this non-parallel result may cause from different domains. In addition, MANOVA results revealed that a statistically significant grade level and school type difference on categories of COLB scores. Other than 11th grade students, 9th and 10th grade students conceptualized learning biology as 'preparing for exams'. Besides, both 9th and 11th grade students preferring learning biology as seeing in a new way and also, 9th grade students viewed learning biology as application. Therefore, the reasons for the differences in grade levels in COLB might be the teaching approaches of biology teachers [24]. Furthermore, the present study revealed that 
in different school types, students might prefer different COLB. For example, students in Religious High School conceptualized the learning biology as 'keeping information in their mind'. The reason of this result might be educational curriculum which is implemented in Religious High School. The school offer more religious instruction and might be needed more 'stored set of information'. Secondly, students in Vocational high school learning biology by preparing for exams and calculating and practicing means that these students prefer lower-level COLB than students in Anatolian High School. The result may be related to the profession and the destination of their choice in the future. Moreover, students in Religious High School had lower mean values in understanding of COLB than students in Anatolian and Vocational High school. It is possible to say that students in Anatolian and Vocational High school learning biology primarily based on the level of a qualitative science learning view. Therefore, learning science contains integrating the newly acquired knowledge with the existing knowledge.

\section{Acknowledgements}

The research was supported by Karamanoğlu Mehmetbey University, The Scientific Research Projects Commission within the scope of the project whose number is $15-\mathrm{M}$ 2014.

\section{References}

1. Bahçivan, E., \& Kapucu, S., Turkish preservice elementary science teachers' conceptions of learning science and science teaching efficacy beliefs: Is there a relationship? International Journal of Environmental \& Science Education, 9(4), 429442, (2014).

2. Benson, P. \& Lor, W., Conceptions of language and language learning. System, 27(4), 459-472, (1999).

3. Boulton-Lewis, G., Marton, F., Lewis, D., \& Wilss, L., A longitudinal study of learning for a group of Indigenous Australian university students: dissonant conceptions and strategies. Higher Education, 47(1), 91-112, (2004).

4. Chiou, G-L., Liang, J-C. \& Tsai, C-C., Undergraduate students' conceptions of and approaches to learning biology: A study of their structural models and gender differences. International Journal of Science Education, 34, 167-195, (2012).

5. Dikmenli, M., \& Cardak, O., A study on biology student teachers' conceptions of learning. Procedia Social and Behavioral Sciences, 2, 933-937. doi: 10.1080/09500690701191425, (2010).

6. Kapucu, S., \& Bahçivan, E., The Differences in senior Turkish pre-service elementary science teachers' conceptions of learning science with respect to gender and socioeconomic status. International Online Journal of Educational Sciences, 6 (1), 41-48, (2014).

7. Lee, M-H., Johanson, R. E., \& Tsai, C-C., Exploring Taiwanese high school students' conceptions of and approaches to learning science through a structural equation modeling analysis. Science Education, 92, 191-220, (2008).

8. Li, W. T., Liang, J. C. \& Tsai, C. C., Relational Analysis of College Chemistry- Major Students' Conceptions of and Approaches to Learning Chemistry. Chemistry Education Research and Practice, 14: 555-565. doi:10.1039/c3rp00034f, (2013).

9. Lin, T.-C., Liang, J.-C., \& Tsai, C.-C., Conceptions of memorizing and understanding in learning, and self-efficacy held by university biology majors. International Journal of Science Education, 37(3), 446-468.. DOI: 10.1080/09500693.2014.992057, (2015). 
10. Marshall, D., Summer, M., \& Woolnough, B. Students' conceptions of learning in an engineering context. Higher Education, 38, 291, (1999).

11. Marton, F., Dall'Alba, G., \& Beaty, E. Conceptions of Learning. International Journal of Educational Research, 19: 277-29, (1993).

12. Sadi, O. \& Lee, M-H., The conceptions of learning science for science-mathematics groups and literature-mathematics groups in Turkey. Research in Science \&Technological Education. doi: 10.1080/02635143.2014.996543, (2015).

13. Sadi, O. \& Uyar, M. The Turkish adaptation of the conceptions of learning science questionnaire: The study of validity and reliability. Journal of Educational and Instructional Studies in the World, 2(10), 73-85, (2014).

14. Saljo, R., Learning in the Learner's Perspective I: Some Commonsense Conceptions. Gothenburg, Sweden: Institute of Education, University of Gothenburg, (1979).

15. Tsai, C-C., Conceptions of learning science among high school students in Taiwan: A phenomenographic analysis. International Journal of Science Education, 26, 17331750, (2004).

16. Purdie, N., Hattie, J. \& Douglas, G., Student Conceptions of Learning and Their Use of Self-regulated Learning Strategies: A Cross-cultural Comparison. Journal of Educational Psychology, 88: 87-100, (1996).

17. Zeegers P., Approaches to learning in science: A longitudinal study. Educ. Psychol, 71, 115-132, (2001).

18. Sadi,Ö., A Phenomenographic approach for exploring conceptions of learning and teaching biology in Turkey. Mevlana International Journal of Education,4(3),124-138 doi:org/10.13054/mije.14.23.4.3, (2014).

19. Tavsancil, E., Measurement of attitudes and data analysis with SPSS. (Second Edition), Ankara: Nobel, (2005).

20. Cokluk, O., Sekercioglu, G. \& Buyukozturk, S., Sosyal bilimler için çok değişkenli istatistik. Tek ve çok değişkenli dağılımlar için sayıltıların analizi, lojistik regresyon analizi, diskriminant regresyon analizi, küme analizi, açımlayıcı faktör analizi, doğrulayıcı faktör analizi, yol analizi. Türkiye: Pegem, (2010).

21. Ozdamar, K., Statistical data analysis with the package program. Eskisehir: Kaan, (1999).

22. Vermunt, J. D., \& Vermetten, Y. J., Patterns in Student Learning: Relationships between Learning Strategies, Conceptions of Learning, and Learning Orientations. Educational Psychology Review, 16 (4): 359-384, (2004).

23. Vîrban, P.S., Gender and educational level differences in the conceptions of learning. Procedia - Social and Behavioral Sciences, 127,812-817, (2014).

24. Virtanen, V., \& Lindblom-Ylänne, S., University Students' and Teachers' Conceptions of Teaching and Learning in the Biosciences. Instructional Science, 38: 355-370, (2010). 